\title{
Dual Band to Wideband Pentagon-shaped Patch Antenna with Frequency Reconfigurability using EBGs
}

\author{
Raimi Dewan', M.K.A. Rahim², M.R. Hamid ${ }^{3}$, M.F.M. Yusoff ${ }^{4}$, H.A. Majid ${ }^{5}$, B.A.F. Esmail ${ }^{6}$ \\ ${ }_{1,2,3,4}$ Department of Communication Engineering, Faculty of Electrical Engineering, \\ Universiti Teknologi Malaysia, Johor, Malaysia; \\ ${ }^{5,6}$ Faculty of Engineering Technology, Universiti Tun Hussein Onn Malaysia, Parit Raja, Johor, Malaysia
}

\begin{tabular}{l} 
Article Info \\
\hline Article history: \\
Received Apr 25, 2018 \\
Revised Jul 12, 2018 \\
Accepted Jul 19, 2018 \\
\hline
\end{tabular}

Keyword:

Dual band

EBG

Frequency reconfigurable

Pentagon patch antenna

Wideband

\begin{abstract}
A dual band to wideband reconfigurable pentagon-shaped antenna with EBG unit cell is proposed. A minimal number of two EBG unit cell is deployed to realize frequency reconfigurable mechanism. By varying the state of the EBG the antenna is capable to change its dual band operation to wideband alternately. There are three cases that have been analysed, first case is the EBG incorporated antenna with ideal and second is with the active EBG. Subsequently, the third cases is the fabricated ideal EBG incorporated antenna. The dual band operation is at $1.8 \mathrm{GHz}$ and $5.2 \mathrm{GHz}$ while the wide band from $1.6 \mathrm{GHz}$ to $2.37 \mathrm{GHz}(770 \mathrm{MHz})$. The proposed reconfigurable antenna is suitable to be implemented for LTE $(1.6 \mathrm{GHz})$, Wi-Fi $(5.2 \mathrm{GHz})$, WiMAX $(2.3 \mathrm{GHz})$ and cognitive radio application.
\end{abstract}

Copyright (c) 2018 Institute of Advanced Engineering and Science. All rights reserved.

\section{Corresponding Author:}

Raimi Dewan,

Department of Communication Engineering,

Faculty of Electrical Engineering,

Universiti Teknologi Malaysia, Johor, Malaysia.

Email: raimidewan@gmail.com

\section{INTRODUCTION}

Metamaterial is a composite material that is engineered to exhibit specific characteristics not found in nature [1], [2]. In microwave engineering, metamaterial is a material that exhibiti non-naturally occurring charateristics at its resonant frequency. The metamaterial ability in manipulating the electromagnetic behaviour is very useful to optimize the performance of the Radio Frequency (RF) and microwave devices, simultaneously adding the flexibility in designing the devices. Some examples of metamaterials are split ring resonators [3], double negative materials, metamaterial lens and absorber, and electromagnetic band gap (EBG) [4]-[6].

EBG is a metamaterial which exhibit band gap charateristics, in phase reflection [7] and high impedance surface. Band gap characteristic of an EBG is a region at which electromagnetic wave (EMW) of designated resonant frequencies are suppressed from passing through it while the remainder EMW of other frequencies can pass through. The band gap is represented by $S_{21}$ parameter which is expressed in decibel (dB) scale. In phase reflection is another distinguished charatericstics at which the EBG exhibit as perfect magnetic conductor (PMC) at the designated frequency. At this frequency, the EBG induces reflected current of EMW in the same phase as the source current. Due to PMC is not naturally existed, EBG that exhibit the PMC characteristic is called as Artificial Magnetic Conductor (AMC). Apart from that, EBG also exhibit real high impedance at its resonant frequency and sometimes referred as High Impedance Surface (HIS). In our research, the band gap characteristics of EBG is utilized.

Reconfigurable antenna is an antenna that can change its properties to fulfilled the ever-changing requirement in wireless communication services (WCS) [8]. The examples of reconfigurable properties of the antenna are frequency, radiation pattern, and polarization. Typical realizations of reconfigurable antennas are 
by implementing the reconfigurable mechanism on the radiating part or on the feeding lines to the antenna. Frequency reconfigurable antenna reduces the potential for interference among wireless communication service that operate at similar frequencies by turning off the unused operating frequency. With interference reduces, the quality of services can be optimized in wireless environment.

In this paper, a dual band to wide band reconfigurable antenna with the use of EBG unit cells is proposed. The antenna is operated at dual band frequency of $1.8 \mathrm{GHz}$ and $5.2 \mathrm{GHz}$ while wideband from 1.6 $\mathrm{GHz}$ to $2.37 \mathrm{GHz}$. By manipulating the state of the EBG unit cells, the band gap is varied which subsequently changing the operating frequency of the antenna. The design of the pentagon-shaped patch antenna only required two EBG unit cells for the reconfigurable mechanism. Antenna is suitable for Cognitive Radio (CR), Long Term Evolution (LTE), Wireless Fidelity (Wi-Fi) and Worldwide Interoperability for Microwave Access (WiMAX) [9], [10].

\section{ELECTROMAGNETIC BAND GAP (EBG) UNIT CELL}

EBG and antenna is designed on low cost FR4 dielectric with thickness, dielectric constant, loss tanget and copper thickness of $1.6 \mathrm{~mm}, 4.39,0.019$ and $35 \mu \mathrm{m}$. Figure 1(a) and Figure 1(b) shows the front and back view of the two EBG unit cells respectively. The EBG at the front side is connected to the ground plane at the back (opposite) side of the subtrate by means of vias. Vias is a shorting pin from the EBG unit cells to the ground. S0 and S1 in Figure 1(b) is the connection from the two VIAS to the ground. Both S0 and $\mathrm{S} 1$ are either simultaneously turn ON or OFF, which are S0S1 $=11$ or S0S1 $=00$ respectively. OFF and ON state is represented by 0 and 1 respectively. Figure 2 shows the band gap changes with respect to changes in EBG state of S0S1. When EBG state is configured to S0S1 $=00$, the band gap of the EBG is appeared at the lower band of 2.31 to $2.5 \mathrm{GHz}$. Band gap at $5.37 \mathrm{GHz}$ to $5.95 \mathrm{GHz}$ is appeared when S0S1 $=11$.

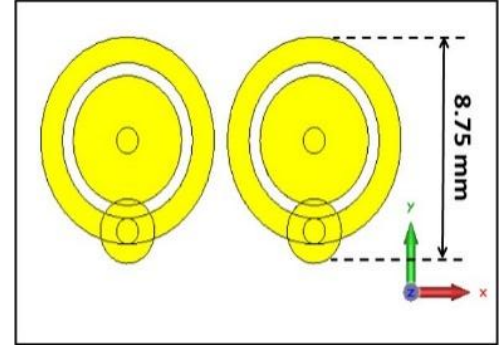

(a)

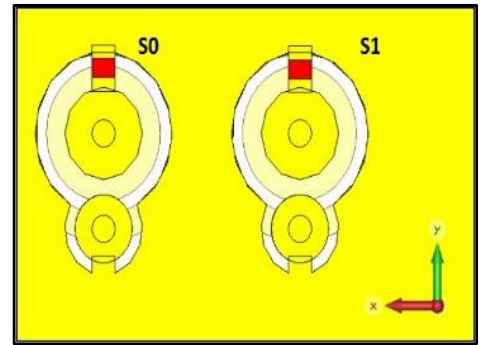

(b)

Figure 1. The (a) front and (b) back view of Two EBG unit cell with $\mathrm{ON}=1$ or $\mathrm{OFF}=0$ switches located at $\mathrm{S} 0$ and $\mathrm{S} 1$

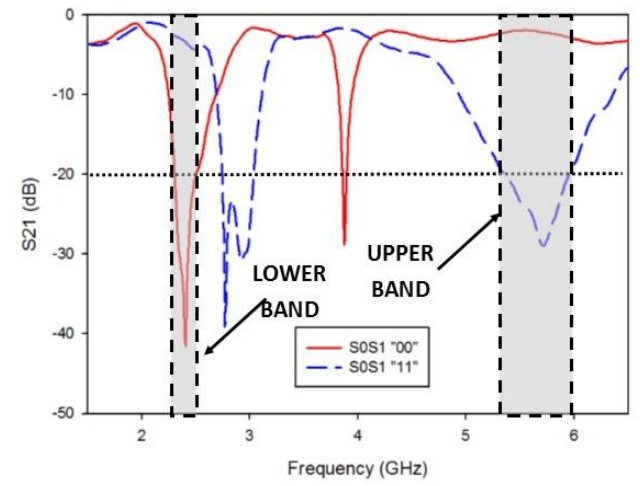

Figure 2. Band gap, S21 of EBG with respect to different EBG State of "00" and "11" 


\section{ANTENNA DESIGN}

A single patch antenna on dual substrate layer is designed and to be incorporated with the EBG to realize a frequency reconfigurable antenna. The antenna designed is separated into two cases: ideal and active case. Firstly, the design of antenna incorporated with ideal EBG is discussed. In ideal case, the OFF and ON of the EBG state is varied by removal and connection of copper strips. Subsequently, antenna incorporated with active EBG is discussed.

\subsection{Ideal case}

In ideal case, the EBG state of of 00 and 11 is reconfigured using copper strips. The copper strip is considered as a perfect switch as the removal and connection provide ideal OFF and ON condition of the EBG. Copper is a good conductance $(\mathrm{ON})$ as conductor whereas removal of copper strip is a good insulator $(\mathrm{OFF})$. Figure 3(a) shows the pentagon-shaped patch antenna on the top FR4 layer. The EBG unit cells are located on the front side of bottom Fr4 layer. Figure 3(b) and Figure 3(c) shows the back side of the bottom substrate layer with EBG state of 00 and 11 respectively.

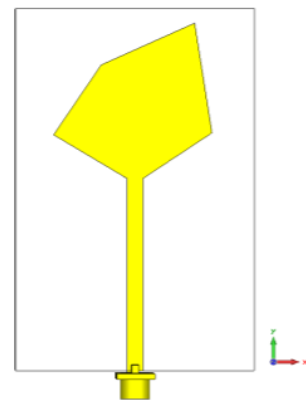

(a)

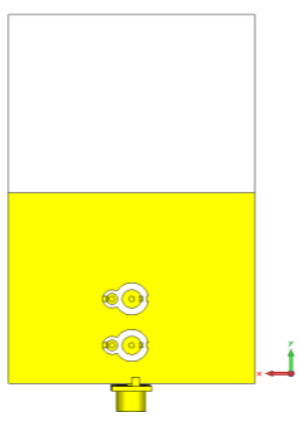

(b)

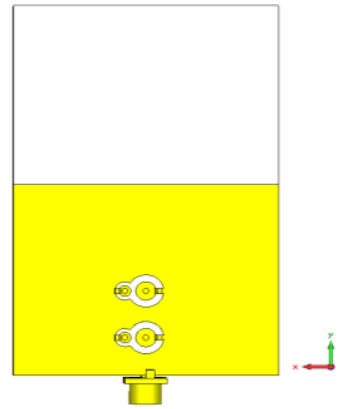

(c)

Figure 3. (a) The simulated front view of the antenna with EBG at the bottom substrate. back view of the antenna with EBG state of (b) 00 and (c) 11

\subsection{Active case}

In practical, the reconfigurable antennas are required to reconfigured electronically. Therefore, the use of copper strips is only serve as proof of concept while active switches are needed to realize a functional reconfigurable antenna for practical use. Figure 4(a) shows the patch antenna with the biasing wires at the back of the bottom substrate. Figure 4(b) shows the positions of the diodes, while Figure 4(c) and Figure 4(d) shows the position of the inductors and capacitor. The overall positions of the diode and the lumped elements are shown in Figure 4(e). Figure 5(a) and Figure 5(b) shows the schematic diagram for the OFF and ON diode with parasitic effect consideration.

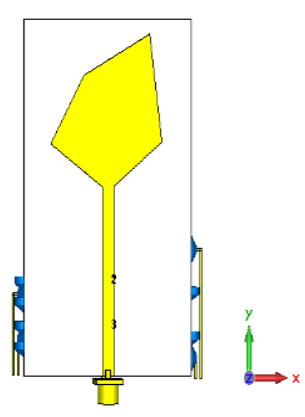

(a)

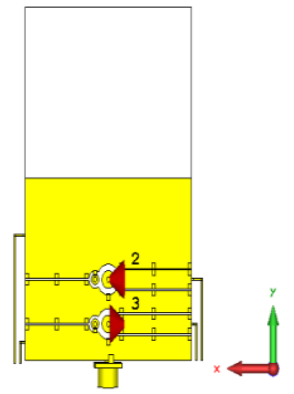

(b)

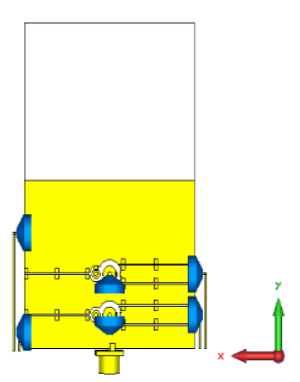

(c)

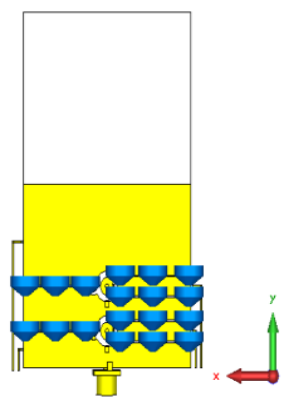

(d)

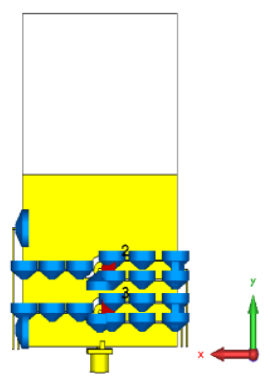

(e)

Figure 3. The (a) front view of the antenna with active EBG. The back view of the antenna with active EBG; positions of (b) the diodes (c) $100 \mathrm{nH}$ inductors (d) $100 \mathrm{pF}$ capacitors and (e) all active and lumped components 


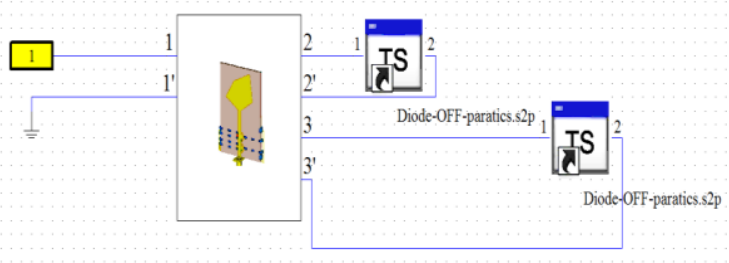

(a)

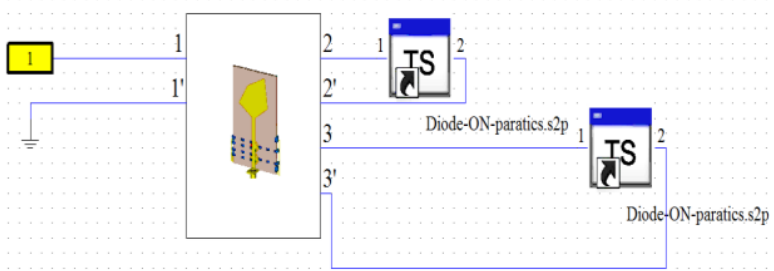

(b)

Figure 4. The Schematic Diagram for Diode in (a) OFF state and (b) ON state with consideration of parasitics

\section{FABRICATION AND MEASUREMENT}

The antenna for ideal case is then fabricated as shown in Figure 6(a)-(d). Figure 6(a) shows the fabricated EBG unit cell which is at the front view of the bottom substrate layer. The via is realized using Platet Through Hole (PTH). Figure 6(b) shows the radiating patch of the antenna while Figure 6(c) and Figure $6(\mathrm{~d})$ is the back view of the bottom FR4 layer with EBG state of 00 and 11 respectively. The antenna is fabricated and measured to compare its performance with the simulated ones. Vector Network Analyzer (VNA) is the measurement device use to take reading of reflection coefficient, $S_{11}$ of the antenna.

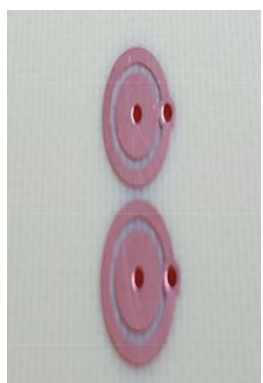

(a)

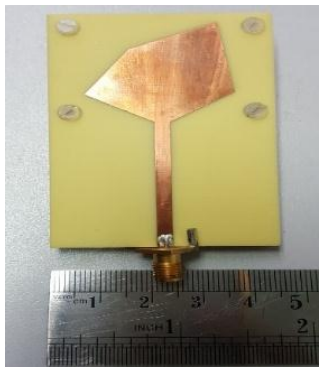

(b)

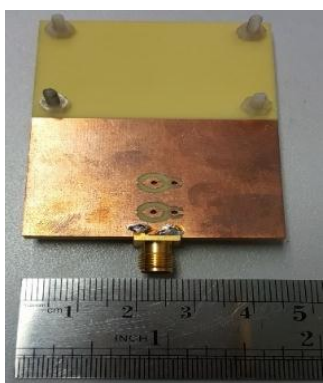

(c)

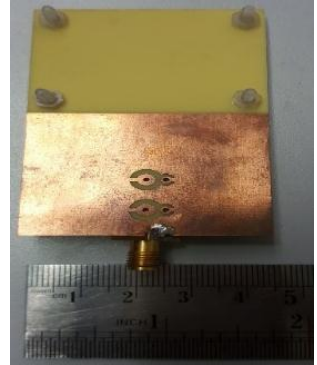

(d)

Figure 5. The fabricated (a) EBG unit cells, the (b) front view of the antenna with EBG unit cells. Back view of the antenna with EBG State of (c) 00 and (d) 11

\section{RESULT AND DISCUSSION}

Figure 7(a) to Figure 7(d) shows the reflection coefficient, $S_{11}$ of the antenna incorporated with EBG of varied state (00 or 11). Figure 7(a) and Figure 7(b) shows the $S_{11}$ result at the lower and upper band respectively, when the EBG state is 00 . As observed from Figure 7(a), the antenna successfully operates at 1.8 GHz for all three cases of ideal (simulation), active (simulation) and ideal (measurement). In Figure 7(b), the antenna is successfully operated at $5.2 \mathrm{GHz}$ for simulation of both ideal and active case. However, the measured result is shifted to the right. This could be due to the imperfection in human error while in fabrication stages, and misalignment that could be occurred between the printed design of multi substrate layer. Any deviation in fabrication affect upper frequencies greater than the lower frequencies due to smaller wavelength of the upper frequency. Small changes in dimension would adversely affect the upper frequency as opposed to the operation at the lower frequency region.

Figure 7(c) and Figure 7(d) shows the $S_{11}$ result at the lower and upper and respectively, when the EBG state is 11. The antenna is successfully operated at wide bandwidth at lower region of $2.3 \mathrm{GHz}$ as shown in Figure 7(c). However, the bandwidth of the measured one is narrow from simulation of both ideal and active case. At the upper region, as shown in Figure 7(d), the antenna is not operated at $5.2 \mathrm{GHz}$ as desired. Table 1 shows the summary of the $S_{11}$ of all cases. Figure 8(a) to Figure 8(d), show the simulated radiation pattern at $1.8 \mathrm{GHz}$ and $5.2 \mathrm{GHz}$ when the EBG is incorporated with the antenna at the EBG state of 00. Figure 9(a) to Figure 9(d), show the simulated radiation pattern at $1.8 \mathrm{GHz}$ and $2.3 \mathrm{GHz}$ when the EBG is 
incorporated with antenna at the EBG state of 11. It can be observed that the antenna radiates in almost omni directional pattern. This is consistent with the patch antenna which have partial ground plane.

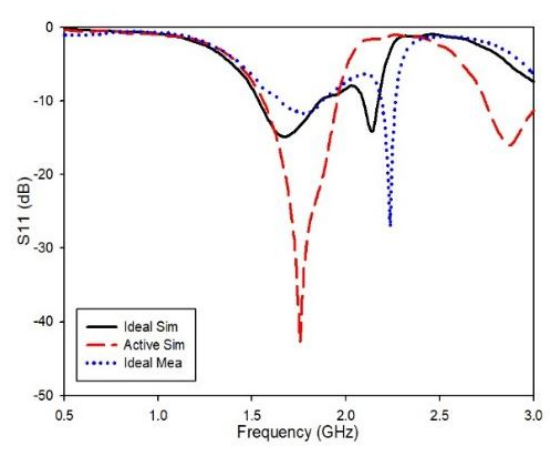

(a)

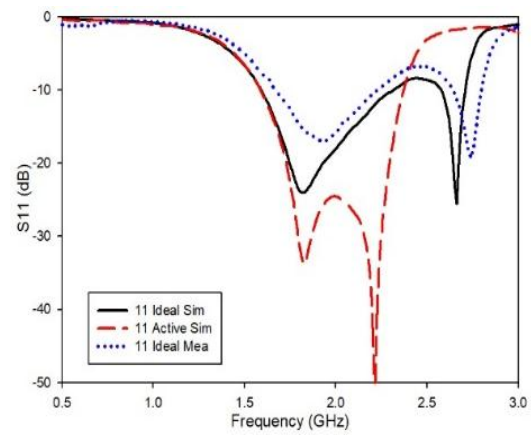

(c)

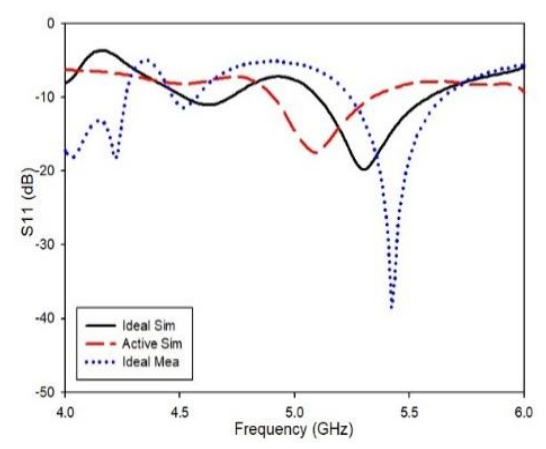

(b)

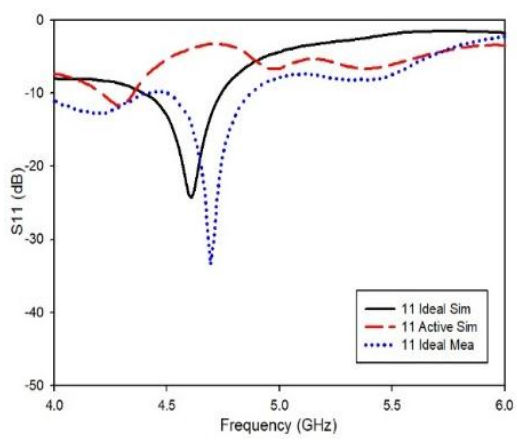

(d)

Figure 6. Antenna reflection coefficient, S11 at (a) lower and (b) upper band with EBG State "00". Antenna reflection coefficient, S11 at (c) lower and (d) upper band with EBG state "11"

Table 1. The Summary of the $\mathrm{S}_{11}$ of all Cases

\begin{tabular}{ccccccc}
\hline Band & \multicolumn{5}{c}{$-10 \mathrm{~dB}$ bandwidth $(\mathrm{GHz})$} & \\
& & & & EBG state 11 & \\
& Ideal (Sim) & Active (Sim) & Ideal (Mea) & Ideal (Sim) & Active (Sim) & Ideal (Mea) \\
\hline Lower & $1.54-1.86$ & $1.56-1.95$ & $1.66-1.86$ & $1.60-2.31$ & $1.59-2.37$ & $1.69-2.22$ \\
Upper & $5.10-5.58$ & $4.92-5.33$ & $5.24-5.64$ & - & - & - \\
\hline
\end{tabular}

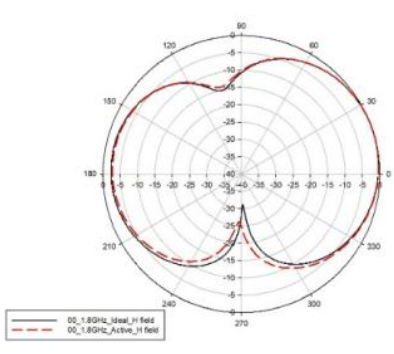

(a)

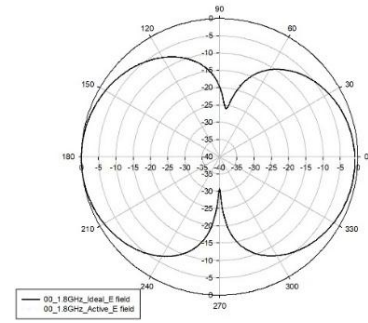

(b)

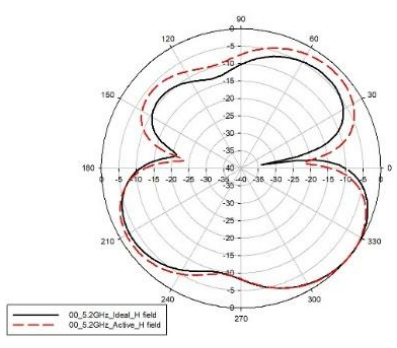

(c)

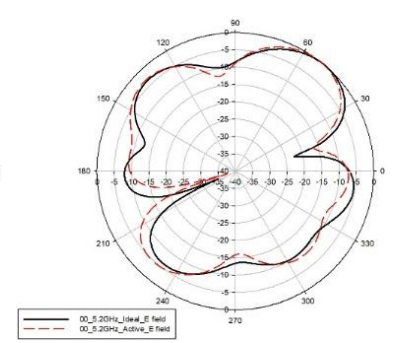

(d)

Figure 7. Antenna radiation patterns with EBG state "00" (a) H-field and (b) E-field at $1.8 \mathrm{GHz}$ (c) $\mathrm{H}$-field and (d) E-field at $5.2 \mathrm{GHz}$ 


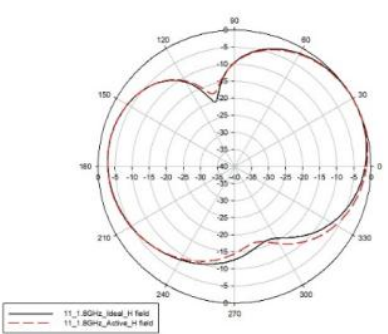

(a)

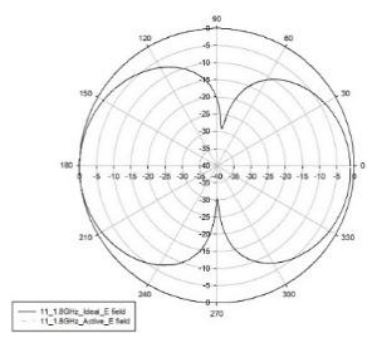

(b)

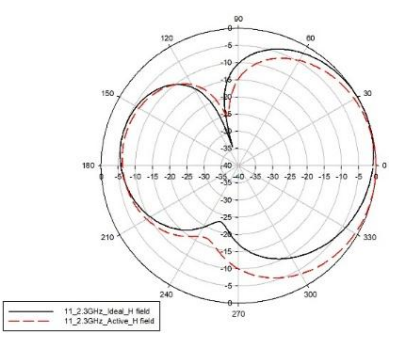

(c)

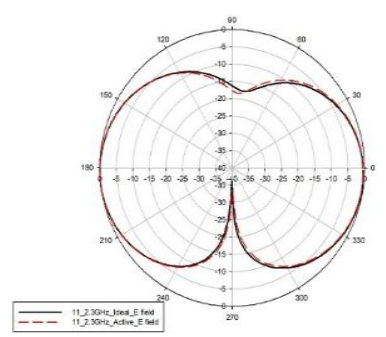

(d)

Figure 8. Antenna radiation patterns with EBG State "11" (a) H-field and (b) E-field at $1.8 \mathrm{GHz}$ (c) $\mathrm{H}$-field and (d) E-field at $2.3 \mathrm{GHz}$

\section{CONCLUSION}

A dual band to wideband reconfigurable pentagon-shaped antenna with EBG unit cell is proposed. By varying the state of the EBG the antenna is capable to change its dual band operation to wideband alternately. The dual band operation is at $1.8 \mathrm{GHz}$ and $5.2 \mathrm{GHz}$ while wide band from $1.6 \mathrm{GHz}$ to $2.37 \mathrm{GHz}$ (770 MHz). The proposed reconfigurable antenna is suitable to be implemented for LTE (1.6 GHz), Wi-Fi $(5.2 \mathrm{GHz})$, WiMAX $(2.3 \mathrm{GHz})$ and cognitive radion application.

\section{ACKNOWLEDGEMENTS}

The authors thank the Ministry of Education (MOE) for supporting the research work; Research Management Centre (RMC), School of Postgraduate Studies (SPS), Communication Engineering Department, Faculty of Electrical Engineering (FKE), and Universiti Teknologi Malaysia (UTM) Johor Bahru under grant no $14 \mathrm{~J} 22$ and $16 \mathrm{H} 08$. The authors would also like to acknowledge all members of ARFMRG.

\section{REFERENCES}

[1] R. Dewan, M. K. A. Rahim, M. R. Hamid, H. A. Majid, M. F. M. Yusoff, and M. E. Jalil, "Reconfigurable Antenna using Capacitive Tuning Metamaterial of Artificial Magnetic Conductor," vol. 1, no. c, pp. 1-2.

[2] P. Singhal and B. Garg, "Design and Characterization of Compact Microstrip Patch Antenna Using' Split Ring' Shaped Metamaterial Structure.," Int. J. Electr., vol. 2, no. 5, pp. 655-662, 2012.

[3] O. Abu Safia, L. Talbi, and K. Hettak, "A new type of transmission line-based metamaterial resonator and its implementation in original applications," IEEE Trans. Magn., vol. 49, no. 3, pp. 968-973, 2013.

[4] G. Lubkowski, R. Schuhmann, and T. Weiland, "Extraction of effective metamaterial parameters by parameter fitting of dispersive models," Microw. Opt. Technol. Lett., vol. 49, no. 2, pp. 285-288, 2007.

[5] O. Ayop, M. K. A. Rahim, N. A. Murad, N. A. Samsuri, and R. Dewan, "Triple band circular ring-shaped metamaterial absorber for x-band applications," Prog. Electromagn. Res. M, vol. 39, pp. 65-75, 2014.

[6] J. P. Turpin, Q. Wu, D. H. Werner, B. Martin, M. Bray, and E. Lier, "Near-Zero-Index Metamaterial Lens Combined With AMC Metasurface for High-Directivity Low-Profile Antennas," Antennas and Propagation, IEEE Transactions on, vol. 62, no. 4. pp. 1928-1936, 2014.

[7] R. Dewan et al., "Artificial magnetic conductor for various antenna applications: An overview," Int. J. RF Microw. Comput. Eng., p. e21105-n/a, 2017.

[8] H. Liu, S. Gao, and T. H. Loh, "Compact MIMO Antenna With Frequency Reconfigurability and Adaptive Radiation Patterns," IEEE Antennas and Wireless Propagation Letters, vol. 12. pp. 269-272, 2013.

[9] M. Abri, H. Badaoui, and Z. Berber, "A Bow-Tie Bluetooth/Wimax Antenna Design for Wireless Networks Applications," Int. J. Inf. Netw. Secur., vol. 1, no. 3, pp. 207-215, 2012.

[10] M. Ahamed, K. Bhowmik, M. Shahidulla, M. S. Islam, and M. A. Rahman, "Rectangular Microstrip Patch Antenna at $2 \mathrm{GHZ}$ on Different Dielectric Constant for Pervasive Wireless Communication," Int. J. Electr. Comput. Eng., vol. 2, no. 3, pp. 417-424, 2012. 


\section{BIOGRAPHIES OF AUTHORS}
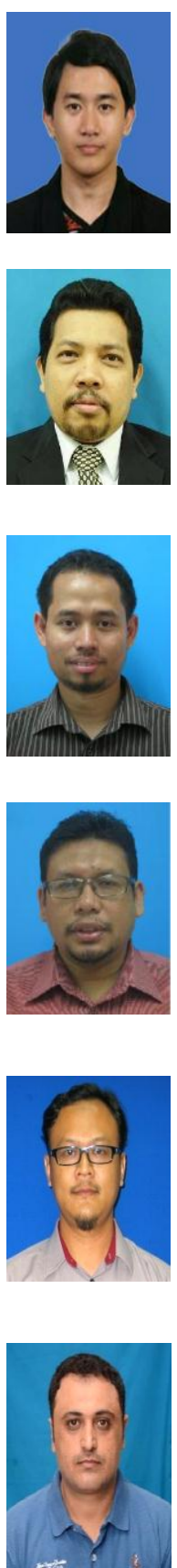

Raimi Dewan received his Bachelor Degree and Master Degree in Telecommunication Engineering from Universiti Teknologi Malaysia (UTM) in 2010 and 2013 respectively. He is currently a research student at the same university. His research interest is in antenna design.

Mohamad Kamal A. Rahim was born in Alor Setar, Kedah, Malaysia in 1964. He obtained his B.Eng. in Electrical and Electronic from University of Strathclyde, U.K. in 1987 and M.Eng. from University of New South Wales, Australia in 1992. He received his Ph.D. in the field of Wideband Active Antenna. He is a Professor at Communications Engineering Department, Faculty of Electrical Enginnering at Universiti Teknologi Malaysia. Professor Mohamad Kamal is a senior member of IEEE since 2007. His research interest includes antennas, metamaterials, body-area communications and reconfigurable antennas.

Mohamad Rijal Hamid received the M.Sc. degrees in communication engineering from the Universiti Teknologi Malaysia, Johor Bahru, Malaysia, in 2001 and the Ph.D Degree at the University of Birmingham, Birmingham, U.K. in 2011. He has been with Universiti Teknologi Malaysia (UTM) at the Faculty of Electrical Engineering (FKE), UTM, since 1999. Currently his position is a Senior Lecturer. His major research interest is reconfigurable antenna design for multimode wireless applications. He was awarded a scholarship from the Universiti Teknologi Malaysia to further study in the U.K.

Mohd Fairus Mohd Yusoff is a graduate faculty member of the Faculty of Electrical Engineering, University Technology Malaysia (UTM). He joined UTM in 2002 as a Tutor. He received his Bachelor in Engineering (Electrical-Telecommunication) in 2002 and Master of Electrical Engineering (Electrical - Electronics and Telecommunications) in 2005 from University Technology Malaysia. He obtained his Ph.D in 2012 from University of Rennes 1, France in area of Signal Processing and Telecommunication. His main research interest and area are antenna design, reflectarray antenna, millimetre waves and microwave devices.

Huda A Majid received the B Eng. degree in Electrical Engineering (Telecommunication) from Universiti Teknologi Malaysia, in 2007. He then obtained his M.Eng in 2010 and PhD degrees in Electrical Engineering in 2013, at Universiti Teknologi Malaysia. He is currently a lecturer in the Department of Electrical Engineering Technology, Faculty of Engineering Technology, Universiti Tun Hussein Onn Malaysia. His research interest includes the areas of design of microstrip antennas, small antennas, Reconfigurable antennas, metamaterials structure, metalaterial antennas and millimeter wave antennas. He has published over 50 articles in journals and conference papers.

Bashar Ali Esmail received the B Eng. degree in Electrical Engineering (Telecommunications) with honours from Ibb University-Yemen, in 2008. He then obtained his M.Eng (Electrical Engineering) in 2016, at Universiti Tun Hussein Onn Malaysia. He is currently a on going $\mathrm{PhD}$ in Electrical Engineering at Electrical Engineering Technolgy Department, Faculty of Engineering Technolgy Universiti Tun Hussein Onn Malaysia. His research interest includes the areas of design of MTM antennas, milimter wave antenna and pattern reconfigurable MTM antenna. 